\title{
ENTRE CINDERELAS E BELAS ADORMECIDAS: REPRESENTAÇÕES FEMININAS NA LITERATURA JUVENIL CONTEMPORÂNEA
}

\author{
PEDRO AFONSO BARTH ${ }^{1}$ \\ Universidade Estadual de Maringá, Departamento de Teorias Linguísticas e Literárias \\ Programa de Pós-graduação em Letras \\ Av. Colombo, 5790 - Jardim Universitário - 87020-900 - Maringá (PR) - Brasil
}

pedroabarth@hotmail.com

\begin{abstract}
Resumo. $O$ objetivo deste trabalho é verificar quais são as representações femininas nas obras de autoria feminina escritas para adolescentes, levando em conta que os contos de fadas clássicos retratam princesas como vítimas fragilizadas. Para tanto, analisamos a obra Cinderela Pop de Paula Pimenta (2015) e O enigma da Adormecida de Simone Marques (2015). A primeira obra é de uma das autoras mais vendidas da atualidade entre adolescentes, a segunda, não é tão conhecida, mas faz parte de uma tendência em ascensão, pois é uma saga fantástica. Na análise verificamos que tanto a nova Cinderela quanto a nova Bela Adormecida ainda possuem características de fragilidade, incoerentes com as representações femininas do século XXI. Assim, o trabalho apresenta reflexões sobre o papel da mediação de leitura no sentido de problematizar e refletir criticamente sobre as representações nessas obras.
\end{abstract}

Palavras-chave: representação feminina; literatura juvenil; contos de fada; discurso literário.

\begin{abstract}
The objective of this work is to verify which are the female representations in the works of female authors written for adolescents, taking into account that the classic fairy tales portray princesses as fragilized victims. For that, we analyze the literary work Cinderela Pop by Paula Pimenta (2015) and O enigma da Adormecida by Simone Marques (2015). The first literary work is one of the best-selling authors of the day among teenagers, the second is not so well known, but it is part of a rising trend, as it is a fantastic saga. In the analysis we verified that both the new Cinderella and the new Sleeping Beauty still have characteristics of fragility, incoherent with the feminine representations of the 21st century. Thus, the paper presents reflections on the role of reading mediation in the sense of problematizing and reflecting critically on the representations in these literary works.
\end{abstract}

Keywords: female representation; youth Literature; fairy tale; literary discourse.

\footnotetext{
${ }^{1}$ Doutorando em Letras pela Universidade Estadual de Maringá (UEM). Atualmente, professor colaborador da Universidade Estadual de Maringá no Departamento de Teorias Linguísticas e Literárias.
} 


\section{CONSIDERAÇÕES INICIAIS}

A confluência do feminismo com os estudos sobre os contos de fadas criou uma sinergia poderosa que tem afetado, radical e permanentemente, o modo como os contos de fadas são produzidos, recebidos, estudados e ensinados. (Alice Neikirk²)

A literatura encapsula discursos e ideologias e durante muito tempo a voz feminina e sua representação não teve espaço. Depois de séculos de silenciamento, a voz feminina encontrou seu lugar na literatura brasileira. A literatura contemporânea de autoria feminina está fortalecida. Abundantes são os exemplos de autoras brasileiras que criaram obras contundentes sobre a posição da mulher na sociedade brasileira, problematizando e trazendo luz a inúmeras questões relativas à identidade feminina. Entretanto, isso só foi possível após décadas de luta feminista e também do fortalecimento da crítica literária feminista que possibilitou a visibilidade das obras escritas por mulheres.

Nesse contexto, é importante indagar: será que o mesmo aconteceu em obras voltadas para o público juvenil? Pensando nessa questão, o presente trabalho tem o objetivo de verificar quais as representações femininas que aparecem em obras da Literatura Juvenil contemporânea escritas por mulheres.

No primeiro momento, quando relacionamos escrita feminina e literatura juvenil, os nomes de Marina Colasanti, Ana Maria Machado, Ruth Rocha, Lygia Bojunga, entre outras, são imediatamente lembrados. As autoras citadas fortaleceram esse filão com qualidade e quantidade, criando obras questionadoras, algumas delas ancorados no maravilhoso e no insólito - e nessas obras, a fantasia é usada como metáfora que lança uma esclarecedora luz sobre a realidade das mulheres brasileiras. Porém, pensar em representações femininas em textos/livros/obras lidas por crianças e jovens significa também lançar um olhar analítico e crítico para textos e obras, que apesar de não terem uma aclamação crítica, são efetivamente consumidas por esse público. Como, por exemplo, Best Sellers e Sagas Fantásticas.

O recorte estabelecido para esta análise será o de obras que recontam ou apresentam relações de intertextualidade com contos de fadas. Contos de Fadas são histórias que dentro de certa medida podem ser consideradas como atemporais, pois mantém uma aura de fascínio. Até hoje elas, muito provavelmente, são as primeiras narrativas que as crianças tomam contato e, por meio delas, que ocorre o acesso ao mundo de imaginação e fabulação. Talvez por isso, a tendência de recontar essas histórias seja tão recorrente. A maioria desses contos possui protagonistas femininas, Branca de Neve, Cinderela, Bela Adormecida... No entanto, todas têm em comum uma postura passiva: em sua maioria são princesas que serão salvas pelo encontro com o príncipe encantado.

Os contos de fadas originais são frutos de um contexto específico, são histórias criadas para atender necessidades da época e se foram contadas e recontadas, é porque seu fascínio se manteve. Sua criação é fundamentada pelos discursos e ideologias que

\footnotetext{
2 No original: "intersection of feminism and fairytale studies created a powerful synergy that has dramatically and permanently affected the way fairy tales are produced, received, studied, and taught" (NEIKIRK, 2009, p. 31).
} 
estavam em voga no momento de sua criação. Conforme a citação de Alice Neirik (2009), epígrafe deste texto, os estudos feministas reconfiguraram a forma com que os contos de fadas são lidos e produzidos. Sendo assim, entendemos que quando um conto de fadas é recontado ou adaptado por uma autora contemporânea, os valores e representações femininas atuais, deveriam encontrar eco. Ou seja, mulheres não devem mais ser representadas como seres indefesos cuja única chance de felicidade é por meio do casamento.

Será que isso efetivamente acontece? Com intuito de analisar criticamente essa questão, lançaremos um olhar para duas obras. A primeira, Cinderela Pop, é de autoria de Paula Pimenta (2015), uma das autoras mais vendidas entre adolescentes e jovens. A segunda é $O$ Enigma da Adormecida, primeiro volume da saga Crônicas do Reino do Portal de autoria de Simone O. Marques (2015). Apesar de não ser muito conhecida, essa obra é integrante de uma tendência contemporânea: as sagas fantásticas, que são narrativas seriais que se desdobram em vários volumes.

Jovens leitores encontram na literatura mais do que uma representação da realidade, há a possibilidade do vislumbre de mundos possíveis. Verificar como autoras contemporâneas mobilizam relações intertextuais com contos de fadas permitirá analisar quais discursos são utilizados e organizados para a representação de personagens femininas: se os mesmos do século XVI e XVII ou se é possível perceber o diálogo com novas representações que emergiram a partir do século XX.

\section{ENTRE A DENÚNCIA E A EXALTAÇÃO: REPRESENTAÇÕES DE MULHERES}

Uma vez que analisamos as representações femininas em obras juvenis contemporâneas, é importante esclarecer o conceito de representação empregado na análise. Roger Chartier (1990) afirma que as representações devem ser entendidas como sendo todas as delimitações, categorizações e classificações que organizam a apreensão do funcionamento da sociedade. A sociedade é organizada por meio da linguagem: são os discursos que estruturam e explicam a realidade a nossa volta. As representações são configuradas pela linguagem e elas encaminham uma forma de compreender as relações entre os indivíduos.

As representações manifestam-se nas práticas da linguagem. Por exemplo, na literatura, como sendo a arte máxima da linguagem, é nela que podemos encontrar representações do mundo e de ideologias que auxiliam na compreensão de seu funcionamento. Chartier (1990) pontua que é fundamental identificar a maneira como, nas práticas, nas representações ou nas produções, se cruzam e se imbricam diferentes formas culturais. Assim, por exemplo, como o texto literário traz consigo representações, ou seja, formas de perceber como o mundo social é organizado, é imperativo analisar a forma que ocorrem essas representações.

Dessa forma, personagens femininos em romances literários durante grande parte da história da Literatura dialogavam com um tipo específico de representação feminina: a mulher passiva aos esquemas de poder do patriarcado. Segundo Lúcia Osana Zolin, a produção literária de autoria feminina pareceu surgir com uma missão específica: contaminar os esquemas representacionais do ocidente que eram feitos pela perspectiva do homem branco, bem situado socialmente. Assim, "a noção de representação, nesse 
sentido, se afasta de sua concepção hegemônica, para significar o ato de conferir representatividade à diversidade de percepções sociais, mais especificamente, de identidades femininas antipatriarcais" (ZOLIN, 2010, p. 186). Ou seja, a literatura feminina passou a ter a responsabilidade de representar um novo perfil de mulher, passou a ecoar a possibilidade de uma nova posição para a mulher na sociedade.

Elódia Xavier (2007), ao pesquisar a representação feminina na ficção, identificou a violência simbólica e a denúncia da falência do sistema patriarcal como suas características basilares. Tais obras evidenciam o que Pierre Bourdieu (2014) aponta na sua obra: a dominação masculina parece estar na "ordem das coisas", porque as sociedades patriarcais cultivaram simbolicamente as noções primitivas de superioridade masculina, parecendo que a proeminência do homem sobre a mulher seja biológica e não cultural. Bourdieu desmistifica isso e prova que há um incessante trabalho coletivo de reprodução de simbolismos que faz com que a dominação masculina se perpetue. $\mathrm{O}$ trabalho coletivo de reprodução é realizado por agentes e por instituições tais como a família, a Igreja, o Estado, a escola, a medicina, os meios de comunicação, entre outros. Assim, representações femininas contemporâneas, em sua maioria, buscam nessa perspectiva o combate aos discursos e simbolismos que colocam a mulher em posição de inferioridade. Destacamos duas representações dos corpos femininos destacados por Xavier (2007): a representação do corpo disciplinado, que obedece às regras sociais e anula sua individualidade e do corpo; e a do corpo violento, que enfrenta o patriarcado de forma agressiva e impede o diálogo.

Porém, por outro lado, outra forma de representação feminina vem ganhando força na ficção brasileira: a representação da mulher liberta das amarras do sistema patriarcal. Aproximando essa representação dos estudos de Xavier (2007) podemos afirmar que se aproxima do que a pesquisadora aponta como a representação do corpo liberado, o corpo que possui liberdade social e psíquica. Para compreender melhor essa representação, recorremos à obra de Alain Touraine, $O$ mundo das Mulheres. Na obra, o autor francês, aponta que a sociedade atual pode ser chamada sociedade das mulheres, pois são elas que ocupam um papel central e definitivo na criação das identidades. Nessa perspectiva, não são apenas vítimas, mas atrizes que consolidam suas funções com uma vitalidade raramente encontrável em outras categorias sociais. As mulheres situam a nova função que elas assumem em um processo de inversão social que nos faz passar para outro tipo de sociedade - a sociedade das mulheres.

Em suma, seja denunciando a violência simbólica sofrida pelas mulheres ao longo dos séculos, seja representando mulheres que desfrutam de uma liberdade sexual, social e psicológica, a literatura feminina conquistou o seu espaço. Zolin (2010, p. 194) afirma que essa literatura "se ainda não é capaz de lhes retratar plenamente a diversidade identitária [as identidades femininas], certamente avança um bom tanto em relação à literatura hegemônica". Assim, temos na Literatura representações de mulheres coerentes com os avanços que vemos na sociedade.

Como anunciamos na introdução, a literatura exercida por grandes autoras da literatura infantil e juvenil, como Marina Colasanti e Ana Maria Machado, apresenta ambas as representações. Indagamos diretamente, nesse trabalho, se o mesmo ocorre em obras contemporâneas que fazem parte de tendências que atraem jovens consumidores, como por exemplo, best sellers com grande campanha de marketing, e obras com características de sagas fantásticas. 


\section{ENTRE CLICHÊS E INOVAÇÕES: CINDERELA POP}

Paula Pimenta é atualmente uma das autoras mais vendidas entre os jovens. A autora se apresenta como escritora de livros cor-de-rosa, pois sua especialidade é escrever histórias com protagonistas adolescentes vivendo aventuras românticas. Provavelmente, essa é a razão principal de sua grande popularidade entre os adolescentes. Um dos seus projetos literários é o desenvolvimento de uma série de livros em que reconta a história de princesas clássicas dos contos de fadas. O segundo volume dessa série, Cinderela Pop, foi escolhido como corpus de análise deste artigo.

Contado em primeira pessoa, a protagonista da trama é Cintia que revive a história da Cinderela. Garota de classe média alta, tinha a vida perfeita até flagrar o pai traindo sua mãe com a secretária: a partir desse instante sua vida apresenta uma grande reviravolta, seus pais se separam, sua mãe vai morar no Japão e ela é obrigada a morar com a tia. Edilene Ribeiro (2006, p. 74) aponta que no conto de fadas clássico, escrito por Charles Perrault, "sempre em andrajos, Cinderela é uma criança em luto pela mãe, subjugada aos poderes e injustiças de sua madrasta". Em Cinderela Pop algo semelhante acontece, mas o luto não é pela perda da mãe e sim pelo fim do casamento dos pais e do conforto financeiro e material.

Para distrair sua mente da infelicidade, Cintia ajuda o namorado da tia a tocar em festas assumindo o nome artístico de DJ Cinderela. Tudo ia bem até o pai forçá-la a ir à festa das filhas gêmeas da sua atual madrasta. Cintia descobre que nessa mesma festa terá de tocar como DJ e se desespera, pois seu pai controlador jamais admitiria que sua filha tivesse que trabalhar. Então, Cintia, sua tia e sua amiga preparam um estratagema para que Cintia possa ir à festa e também consiga ser DJ: uma fantasia com máscara para DJ Cinderela e depois mudando de roupa iria para festa.

A presença do pai de Cinderela é uma diferença substancial em relação ao conto clássico. Se no conto de fadas a ausência do pai deixa a protagonista à mercê da madrasta, em Cinderela Pop, o pai tem uma presença autoritária e intimidadora. É ele que permite que a madrasta tenha poder sobre Cintia, e por temê-lo que Cintia usa uma máscara para trabalhar com DJ. Ou seja, se no conto de fadas original a maldade apresenta contornos femininos, na versão de Pimenta, a figura masculina valida e encoraja os atos de vilania.

Mascarada e tocando música pop, DJ Cinderela atrai a atenção de um moço também mascarado que vai até a cabine de som e eles têm uma conversa intensa. Ambos se impressionam um com o outro. E reparam que estão usando tênis All Star. Próximo da meia noite, DJ Cinderela se afasta da cabine, troca sua fantasia por um vestido cor de rosa e se transforma em Cintia e vai procurar o menino que a impressionou. E o encontra... no palco. Ela descobre que ele é Fredy Prince, um cantor adolescente famoso. Tendo que sair às pressas da festa, deixa para trás um dos seus All Star. Fredy encontra o sapato e usando sua fama, mobiliza redes sociais para encontrar sua cinderela - cujo rosto não conhece. A substituição do sapatinho de cristal por um tênis de uma marca específica é um elemento bastante significativo da obra contemporânea. A marca está atrelada a uma postura despretensiosa, descolada. Outra forma de caracterização são as músicas tocadas pela DJ Cinderela. São todas mencionadas pela narrativa e podem gerar uma identificação entre os leitores adolescentes.

A partir desse ponto da narrativa, Cintia tenta se revelar para Prince, mas sem sucesso, pois sua madrasta e as filhas tentam impedir. A trama avança e Cintia acaba 
tendo que morar com o pai e a madrasta. No ápice da narrativa, acontece a festa de formatura de Cintia - em que Fredy Prince faria sua última apresentação antes de viajar para longe, portanto, seria a sua última chance de encontrar seu príncipe. Porém, a madrasta, por meio de artimanhas, faz com que Cintia fique de castigo e não possa ir até o baile. Eis que surge sua mãe, vindo diretamente do Japão, que tira a filha da clausura e a arruma lindamente para o baile. O resto da história é previsível: Cintia encontra Prince, e ele encaixa o All Star em seu pé.

Em suma, Cinderela Pop apresenta a mesma estrutura do clássico conto de fadas. As inovações trazidas pelo contexto contemporâneo, o uso de redes sociais, blogs no meio da narrativa, não mascaram que a protagonista mantém a mesma postura passiva da Cinderela clássica. Ribeiro ao estudar o conto da Cinderela clássico, escrito por Charles Perrault, aponta como a protagonista depende do príncipe para ter ascensão sobre as adversidades, pois "é por meio de um processo de reconhecimento - a 'prova do sapatinho' que ela encontrará seu 'salvador', aquele que a restituirá à sua posição privilegiada - a de princesa (RIBEIRO, 2006, p. 74). Cinderela Pop, mesmo ambientada no século XXI apresenta a mesma estrutura: Fredy Prince que traz a felicidade para Cintia e é ele que possibilita sua salvação.

Cintia, enquanto representação feminina, não apresenta nenhum tom de denúncia contra o que Bourdieu (2003) denomina como dominação masculina e nem é consciente de independência, não permitindo ser considerada detentora de um espírito livre das amarras do gênero, como apregoa Alain Touraine (2007). Cintia é simplesmente uma garota sonhadora que apenas encontra sua realização por meio de um príncipe e não consegue lutar contra a adversidade sozinha - sempre há uma ajuda externa, seja da tia, da mãe que voltou do Japão ou a interferência direta de Fredy Prince. A personagem é modernizada em sua superfície - pelo fato de usar All Star, ser DJ, ter redes sociais, tocar e gostar de músicas atuais. Mas a sua atitude ainda é refém de uma passividade histórica presente em relação às mulheres.

A mãe de Cintia, que se separou do marido opressor e foi para o Japão e tem uma bem-sucedida carreira como arqueóloga, poderia ser um exemplo de representação feminina de um corpo liberado - nomenclaturas utilizadas por Elódia Xavier (2007). Mas não é o que verificamos. A personagem é mais próxima de um corpo disciplinado: só se libertou do marido opressor por interferência externa e ainda parece crer que uma mulher só encontra a plenitude por meio de uma relação amorosa com um homem. Podemos afirmar ancorados em um trecho da obra, que durante um diálogo com a filha a personagem exclama: "Você costumava ser tão romântica e sonhadora... e de repente virou uma pedra de gelo! Torço muito pra que apareça alguém que derreta o seu coração. Quem sabe não vai ser esse príncipe aí que vai salvar você de si mesma?" (PIMENTA, 2015, p. 64).

A própria mãe acredita que a filha encontrará sua plenitude quando conhecer um homem. Os estudos, a profissão de Cintia, sua perspectiva de futuro, sua compreensão sobre os atos do pai são minimizados e não merecem grande aprofundamento na obra. $\mathrm{O}$ destaque absoluto é na busca do amor de Prince, amor este que a "salvaria". E talvez seja essa a representação principal da leitura da obra: a busca por um príncipe perfeito que trará consigo a felicidade plena.

Outro aspecto em relação à representação feminina de Cinderela Pop é a importância da beleza física. Observamos a descrição de Cintia, antes de um dos bailes: 
quando me olhei no espelho, apenas para ver se estava tudo no lugar, fiquei admirada com o que vi. A Lara e minha tia haviam feito uma mágica! O meu cabelo castanho-claro, normalmente liso e sem graça, estava brilhante, dourado, cheio de cachos que caiam pelas minhas costas. A sombra levemente esverdeada realçou os meus olhos da mesma cor. Até a minha boca tinha ficado mais viva com o gloss corde-rosa que elas tinham me obrigado a usar. Tive que admitir que eu estava... bonita. (PIMENTA, 2015, p. 54)

A aparência de princesa, a beleza exuberante, característica imprescindível das princesas dos contos de fadas aparece como principal característica de Cintia. Por mais que o Fredy Prince tenha se apaixonado por ela mascarada, a descrição de seu aspecto físico a aproxima da Cinderela Clássica e da sua dependência da beleza. Esse aspecto fica ainda mais claro, quando em uma entrevista, o cantor adolescente, quando indagado sobre sua princesa do conto de fadas favorita, responde:

Fredy Prince: Que difícil...Todas as princesas têm seus encantos. Adoro os cabelos da Ariel, a voz da Bela Adormecida, a meiguice da Branca de Neve, a inteligência da Bela... Sem falar que todas elas têm o corpo perfeito! Mas acho que se eu tivesse que escolher uma, ficaria com a Cinderela... Aquela menina tem que ter alguma coisa a mais para o príncipe ter batido o olho e se apaixonado de primeira, mesmo com o salão lotado de gatas! Gostaria muito de descobrir que 'coisa' é essa.... (PIMENTA, 2015 p. 83)

A partir da fala de Fredy Prince podemos elencar os critérios estabelecidos para uma menina ser uma princesa digna: corpo perfeito e ser a escolhida do homem. A opinião da garota parece não importar. Fica implícita a ideia de que se Cintia não tivesse um corpo perfeito como as princesas dos contos de fadas, ela não interessaria o "príncipe".

Também podemos considerar que, apesar de adolescente, a obra apresenta uma forte apologia ao casamento. Segundo Ribeiro, a necessidade da busca pela realização matrimonial tal qual acontece em Cinderela e outros tantos contos de fadas, é uma convenção social, pois "desde cedo, as meninas crescem esperando amarem, casarem, viverem felizes para sempre e, quando isso não acontece, a decepção surge de forma avassaladora, pois à mulher foi apregoado que esses passos eram necessários para sua felicidade" (RIBEIRO, 2006, p. 79). Cinderela Pop alimenta essa representação e em nenhum momento aponta para a desconstrução dessa convenção social.

Cinderela Pop, enquanto obra juvenil apresenta muitas qualidades, como um projeto gráfico atraente para adolescentes, uma escrita ágil e fluída, multimodalidade que constitui a obra por meio do uso de redes sociais, blogs, tweets, entre outros elementos gráficos. Entretanto, em relação à representação feminina não há nenhuma inovação, podemos afirmar que Cintia, uma garota do século XXI, apresenta as mesmas atitudes e os mesmos valores de uma camponesa do século XVI. Em seguida, verificaremos se o mesmo ocorre em $O$ Enigma da Adormecida. 


\section{ENTRE MISTÉRIOS E SILENCIAMENTOS: O ENIGMA DA ADORMECIDA}

O livro O Enigma da Adormecida pode ser caracterizado como o início de uma saga fantástica. Sagas Fantásticas, segundo Alberto Martos García (2009), são histórias serializadas, multimediais, que ocorrem em um universo inventado. Ou seja, são narrativas que se desdobram em mais de volume e são passíveis de continuações, além de utilizar mapas, desenhos e ilustrações para auxiliar o leitor na compreensão do mundo inventado. Histórias como Harry Potter e Senhor dos Anéis são exemplos de sagas fantásticas que obtiveram um grande sucesso entre crianças e jovens. Sucesso que fomentou o surgimento de sagas escritas por autores brasileiros.

A história de Marques é apresentada livremente inspirada no desenho animado Caverna do Dragão e em games inspirados em histórias nas quais garotos comuns são jogados em realidades fantásticas. O universo criado por Simone O. Marques pode ser considerado como uma Saga Fantástica: a história se passa em um mundo mágico, em que seres mágicos e acontecimentos inexplicáveis ocorrem o tempo todo, a narrativa se desdobrará em vários volumes, há mapas e paratextos na edição do livro, para orientar os leitores na compreensão do mundo inventado. A narrativa inicia com sete jovens despertando em um celeiro, quatro garotos e três garotas. Cada um com uma personalidade marcante. Estão assustados, pois não se conhecem e não fazem a menor de ideia de como foram para naquele lugar. Logo, percebem que junto a eles há uma bela donzela que não despertou, continua adormecida.

Marcelo assume a liderança do grupo e começa a explorar o local desconhecido. Os sete jovens - sempre levando a adormecida - envolvem-se em várias situações até encontrar um castelo, em que uma simpática criatura, uma espécie de duende anciã entrega a cada um deles um baú e revela que Marcelo é o rei de todos, e a menina adormecida sua Rainha, e que sua missão é descobrir a melhor maneira para despertá-la. Apenas acordando-a, ele conseguirá salvá-la de um terrível mundo de pesadelos que está a matando lentamente. Ou seja, temos na história a autoridade máxima e inquestionável sendo de um homem, o rei escolhido, que é soberano e salvador - especialmente do destino da Adormecida.

Diferente de Cinderela Pop, O enigma da Adormecida não é somente uma adaptação do conto com elementos contemporâneos. Há mais personagens, tramas e complexidade. Porém, o grande mistério da narrativa é a jovem e bela moça que está adormecida. E toda a sua trama apresenta semelhanças com o conto clássico original. Como as princesas do conto, a beleza da adormecida é deslumbrante e encanta a todos.

Bela estava limpa e perfumada. Sua pele clara, livre de fuligem, parecia luminosa. Seu rosto delicado estava rosado e seus lábios eram macios e vermelhos. Os cílios escuros sobre a pele clara indicavam que ela ainda dormia profundamente. Usava um vestido branco, com mangas compridas e fofas. Os pés pequenos estavam descalços. Marcelo soltou a respiração que nem percebeu ter segurado. (MARQUES, 2015, p. 47)

A descrição aponta a aura de fragilidade e feminilidade. A menção aos pés pequenos nos lembra de o que Bourdieu (2003) postula como uma estratégia de dominação do masculino: o feminino sempre precisa ser menor, contido, protegido. Além do mais, A Bela Adormecida aponta para uma metáfora da personalidade feminina frente aos valores impostos por uma sociedade patriarcal (RIBEIRO, 2006, p. 74). Importante postular que 
a simples utilização de uma relação intertextual com a figura da Bela adormecida não significa que a representação da mulher é a mesma do conto de fadas. Pode ocorrer uma reconfiguração dos elementos que possibilita a desconstrução do estereótipo. Mas não é isso que ocorre na narrativa de Simone O. Marques, como podemos observar no momento que Marcelo desperta a Bela Adormecida com um beijo.

- Luana... acorde para seu Rei... - e deslizou os lábios selando a frase com um beijo suave nos lábios pálidos.

Todos no quarto ouviram o longo suspiro que saiu dos lábios dela. Marcelo a olhava com o rosto muito próximo ao dela. Ela a ouviu suspirar e acariciou seus cabelos. Esperou. Todos esperaram. Então ela, lentamente, levantou a mão e tocou a pedra ônix em seu peito, apertando-a, depois abriu os olhos violeta, seus lábios pálidos se desenharam num sorriso, e ela levou a mão ao rosto dele numa carícia suave e sentiu sob os dedos as lágrimas que desceram pelo rosto de seu Rei. (MARQUES, 2015. p. 159)

Sem Marcelo, sem a bravura masculina, a Adormecida - que descobrimos chamarse Luana - jamais acordaria. Ou seja, exatamente a mesma relação estabelecida no conto original, na versão de Charles Perrault, como aponta Ribeiro (2006, p. 74) "implicitamente, no conto, percebe-se a força do príncipe em relação à fragilidade da princesa que, sem a coragem masculina, não poderia ver-se salva da maldição apregoada inicialmente - um longo período de sono" (RIBEIRO, 2006, p. 74). Dessa forma, podemos considerar que $O$ Enigma da Adormecida reforça a representação do homem como salvador e provedor, enquanto "a mulher vive o papel passivo de quem está sempre à espera de "salvação", permitindo aos outros que façam de sua vida o que bem quiserem" (RIBEIRO, 2006, p. 76-77).

Entretanto, Luana não é a única personagem feminina com destaque na obra. Há três garotas, Adriana, Fernanda e Mônica. Porém, nenhuma delas apresenta um comportamento que poderia ser caracterizado como um corpo liberado, um corpo feminino livre e independente. Todas as personagens femininas apresentam uma dependência de algum tipo de proteção masculina. Após despertar, Luana não sabe quem é, e passa a depender de Marcelo para tudo. Por sua vez, Adriana permanece presa ao estereótipo de mãe solteira, que abandonou sua vida devido a uma gravidez precoce. Fernanda tem uma personalidade passiva e mimada, vem de uma família rica e sempre busca a proteção masculina. Já Mônica, tem uma personalidade forte e atrevida, mas no decorrer da obra, é retratada como uma personagem ciumenta e negativa, pois sente ciúmes da relação de Marcelo e Luana e começa a alimentar desejos destrutivos.

Porém, é preciso considerar que as personagens estão em uma saga. Sagas fantásticas são histórias que se desdobram em vários volumes e podem ter ampliações. Assim, as personagens podem apresentar evoluções durante a continuação da história e ganhar maiores contornos.

A principal diferença entre Cinderela Pop e $O$ Enigma da Adormecida é o papel do maravilhoso. Na primeira, temos uma obra ligada à realidade, sem a utilização de recursos fantásticos e soluções mágicas. Já na Obra de Simone Marques, a magia e a fantasia estruturam a narrativa e a sua continuação implica que as personagens ainda poderão evoluir. 


\section{E AGORA? UM PASSO PARA FRENTE E DOIS PASSOS PARA TRÁS?}

Verificamos nas seções anteriores, que nem a representação contemporânea de Cinderela e nem a de Bela Adormecida apresentam uma ruptura com as personagens clássicas dos contos de Charles Perrault. Pelo contrário, pois tanto estas quanto aquelas são "histórias que refletem o discurso da fragilidade feminina e escondem a necessidade de as mulheres começarem a articular seus próprios valores e opiniões" (RIBEIRO, 2006, p. 74). Dessa forma não temos nem representados corpos femininos que denunciam o passado e o presente de dominação e opressão do feminino pelo masculino e nem obras que representam mulheres como verdadeiras protagonistas de suas vidas.

A análise das duas obras poderia lançar uma sombra sobre a questão da representação feminina em livros contemporâneos de Literatura Juvenil. Isso porque podemos pensar que tais obras significam um retrocesso. Porém, isso não tira a evolução e o crescimento das obras de dezenas de autoras como Marina Colasanti, Lygia Bojunga, Ana Maria Machado em relação à representação feminina. Entretanto, é necessário pontuar sagas fantásticas e autoras populares como Paula Pimenta, aparecem com mais facilidade nas listas dos livros mais vendidos pelas livrarias e mais acessados em blogs e redes sociais.

Portanto, antes de qualquer julgamento valorativo é preciso destacar que a obra de Paula Pimenta e sagas fantásticas como $O$ enigma da Adormecida são avidamente consumidas por adolescentes. E isso é explicável: a primeira é uma obra escrita especialmente para meninas adolescentes, com um projeto gráfico muito atraente, escrito por uma autora que sabe agradar o mercado e atingir o público. Já as Sagas Fantásticas são um fenômeno ascendente que têm um público com um perfil específico: jovens leitores que amam fantasia, histórias representadas em diferentes mídias.

O objetivo deste trabalho foi o de alertar sobre as representações femininas na literatura contemporânea juvenil e ressaltar a importância dos mediadores de leitura no processo de apresentação e ampliação do repertório de leituras dos jovens leitores. Mediadores de leitura, professores e leitores críticos precisam perceber quando as representações de mulher dão um passo para trás. Portanto, dirigir um olhar crítico para livros como Cinderela Pop e $O$ enigma da Cinderela é fundamental, mas não para condenar sua leitura ou perseguir seus leitores. Pelo contrário, temos que partir da premissa que todos os percursos de leitura são válidos e merecem ser respeitados.

Nesse contexto, é preciso indagar: porque em pleno século XXI temos a reiteração da representação da mulher como um corpo submisso e indefeso cuja única chance de felicidade é pelo casamento? Não é possível ter uma resposta objetiva, entretanto é importante pontuar que a literatura representa os jogos de poder que vemos na sociedade. A Literatura Juvenil, talvez mais do que as outras, sofre grande influência do mercado e do capitalismo de ficção. Ou seja, se são produzidas obras como Cinderela Pop é porque elas vendem, elas atraem leitores, elas geram identificação.

Portanto, é importante analisar e compreender as razões da popularidade de obras como Cinderela Pop e criar meios de desconstruir as representações que as obras apresentam. O compromisso de educadores e mediadores de leitura é com a formação de leitores críticos que consigam perceber e desmontar as representações existentes em obras como as analisadas neste trabalho. A melhor forma talvez seja a apresentação de outras obras, que apresentam outras representações do corpo feminino. Ao mesmo tempo em 
que existem obras que perpetuam o estereótipo da princesa indefesa, existem obras que denunciam a opressão contra a mulher ou exaltam a liberdade da condição feminina. $\mathrm{O}$ que deve ser feito é uma ponte entre as duas. Os leitores têm o direito de conhecer e transitar entre diferentes repertórios de leituras para assim consolidar uma visão crítica do mundo em que vivem.

\section{REFERÊNCIAS}

BOURDIEU, P. A Dominação Masculina. Trad. Bras. Rio de Janeiro: Bertrand Brasil, 2003. CHARTIER, R. O mundo como representação. Estudos Avançados, São Paulo, v. 5, n. 11, 1991. MARQUES, S.O. O enigma da Adormecida. Crônicas do Reino do Portal. São Paulo: Madras, 2015.

MARTOS GARCIA, A. Introducción al... mundo de las sagas. Badajoz: Universidad de Extremadura, 2009.

NEIKIRK, A. '...Happily Ever After' (or What Fairytales Teach Girls about Being Women). Hohonu [a Journal of Academic Writing], v. 7, 38-42, 2009.

PIMENTA, P. Cinderela Pop. Rio de Janeiro: Galera Record, 2015.

RIBEIRO, E. Fragilidade e força: personagens femininas em Charles Perrault e no mito da donzela Guerreira. Brasília: Éclat, 2006.

TOURAINE, A. O mundo das mulheres. Rio de Janeiro: Vozes, 2007.

XAVIER, Elódia. Que corpo é esse? O corpo no imaginário feminino. Florianópolis: Ed. Mulheres, 2007.

ZOLIN, L.O. Questões de gênero e de representação na contemporaneidade. Revista Letras, n. 41, 183-195, jul./dez. 2010.

Artigo recebido em: fevereiro de 2018.

Aprovado e revisado em: agosto de 2018.

Publicado em: dezembro de 2018.

Para citar este texto:

BARTH, Pedro Afonso. Entre cinderelas e belas adormecidas: representações femininas na literatura juvenil contemporânea. Entremeios [Revista de Estudos do Discurso, ISSN 2179-3514, on-line, www.entremeios.inf.br], Seção Temática [Discurso, arte e literatura - Parte II], Programa de Pós-Graduação em Ciências da Linguagem (PPGCL), Universidade do Vale do Sapucaí (UNIVÁS), Pouso Alegre (MG), vol. 17, p. 289-299, jul. - dez. 2018.

DOI: http://dx.doi.org/10.20337/ISSN2179-3514revistaENTREMEIOSvol17pagina289a299 